\title{
umpilnovatif \\ Pengembangan Buku Pop Up Untuk Kegiatan Bercerita Anak di PAUD Bougenville
}

\author{
Ridhagitha Kurnia, ${ }^{1 \otimes}$ Retno Widyaningrum $^{2}$, Diana Ariani ${ }^{2}$ \\ ${ }^{1}$ Universitas Negeri Jakarta, Jakarta, Indonesia. \\ ${ }^{2}$ Universitas Negeri Jakarta, Jakarta, Indonesia. \\ 3 Universitas Negeri Jakarta, Jakarta, Indonesia.
}

DOI: https://doi.org/10.21009/JPI.022.05

\begin{tabular}{|c|c|}
\hline Article History & Abstrak \\
\hline Received : 2019 & \\
\hline $\begin{array}{l}\text { Accepted : } 2019 \\
\text { Published : } 2019\end{array}$ & $\begin{array}{l}\text { Penelitian pengembangan ini bertujuan untuk menghasilkan produk berupa buku } \\
\text { cerita pop up. Buku ini sebagai media pembelajaran yang dimanfaatkan untuk } \\
\text { kegiatan bercerita anak pada Kelompok Bermain di PAUD Bougenville. Penelitian }\end{array}$ \\
\hline Keywords & $\begin{array}{l}\text { pengembangan ini dilakukan dengan mengikuti prosedur model pengembangan Baker } \\
\text { \& Schutz, yakni 1) Formulasi Produk, 2) Spesifikasi Pembelajaran, 3) Uji Coba Soal, 4) }\end{array}$ \\
\hline $\begin{array}{l}\text { Development of } \\
\text { Learning Media, Pop } \\
\text { Up Story Books, } \\
\text { Children's Storytelling } \\
\text { Activities, } \\
\text { Development Model } \\
\text { Baker E Schutz. }\end{array}$ & $\begin{array}{l}\text { Pengembangan Produk, 5) Uji Coba Produk, 6) Revisi, dan 7) Analisis Operasi. } \\
\text { Evaluasi pada penelitian pengembangan produk ini dilakukan melalui Expert Review, } \\
\text { dan Field Test. Tahap expert review melibatkan } 1 \text { orang ahli materi dan } 1 \text { orang ahli } \\
\text { media. Nilai rata-rata yang diperoleh pada tahap ini sebesar } 3,7 \text { sehingga kualitas } \\
\text { media dapat dikategorikan sangat baik. Tahap field test buku cerita pop up di uji } \\
\text { cobakan kepada } 15 \text { orang siswa, kemudian guru menilai menggunakan lembar } \\
\text { penilaian observasi. Pada tahap ini diperoleh nilai rata-rata keseluruhan } 88 \% \text {, dari } \\
\text { hasil tersebut dapat dikategorikan bahwa buku pop up berjudul "Liburan ke Kebun }\end{array}$ \\
\hline & $\begin{array}{l}\text { Binatang" dikatakan baik digunakan dalam kegiatan bercerita. Maka, dapat } \\
\text { disimpulkan bahwa pada penelitian pengembangan ini menghasilkan sebuah produk } \\
\text { berupa Buku Pop Up Tema Binatang yang digunakan untuk kegiatan bercerita anak } \\
\text { pada Kelompok Bermain di PAUD Bougenville. }\end{array}$ \\
\hline
\end{tabular}

\begin{abstract}
Abstrak
This development research aims to create product in the form of pop up story books. This book is a learning medium that is used for storytelling activities in a Play Group named Bougenville. This development research was carried out by following the Baker $\mathcal{E}$ Schutz development model, which consist of 1) Formulation, 2) Instructional Specification, 3) Item Tryout, 4) Product Development, 5) Product Tryout, 6) Product Revision, and 7) Operation Analysis. The product evaluation is done through Expert Review and Field Test. The expert review phase involves 1 subject matter expert and 1 media expert. The average score obtained from experts review is 3.7 which considered as very good. For field test, the pop up story book has tested on 15 students, The average score obtained at this phase is $88 \%$ which considered as good. So, it can be concluded, this development research has created an Animal Theme Pop Up Book which used for storytelling activities in Bougenville Play Group.
\end{abstract}

Corresponding author : Ridhagitha Kurnia

Adress: Jl. Rawasari Selatan 2 No.30A RT.014/oo2

(C) 2019 Universitas Negeri Jakarta

Cempaka Putih Timur, Cempaka Putih

Jakata, 10510

E-mail: ridha.gita@gmail.com 


\section{PENDAHULUAN}

Pendidikan merupakan sesuatu hal yang sangat penting bagi kehidupan seorang anak. Setiap anak mempunyai bakat dan potensi masing-masing. Bakat dan potensi ini dapat digali dan dikembangkan melalui pendidikan sehingga anak tersebut pada akhirnya akan memiliki prestasi. Pendidikan yang didapat anak pertama kali adalah pendidikan dari keluarga, kemudian anak terus tumbuh dan berkembang untuk selanjutnya anak dipersiapkan untuk dapat masuk ke dalam pendidikan formal. Persiapan anak memasuki pendidikan formal dapat dilakukan dengan mengikuti sebuah kelompok bermain, agar anak dapat terlatih berinteraksi dan dapat beradaptasi dengan lingkungan yang baru. Kelompok bermain sendiri termasuk ke dalam jenis Pendidikan Anak Usia Dini (PAUD).

Di dalam kurikulum yang dilaksanakan PAUD Bougenville terdapat salah satu kegiatan belajar yaitu anak bercerita kepada temantemannya mengenai pengalaman atau kejadian sederhana dengan tema cerita "Liburan ke Kebun Binatang". Kegiatan bercerita ini kurang mendapatkan minat dari para peserta didik, karena guru belum memiliki media yang dirasa tepat dan sesuai dengan tema cerita yang seharusnya, padahal kegiatan bercerita ini mempunyai tujuan anak dapat meningkatkan kemampuan bercerita yang dimiliki. Selain itu latar belakang guru di PAUD Bougenville yang bukan merupakan lulusan PAUD juga menjadi kendala karena kurangnya pengetahuan untuk menarik minat siswa.

Berdasarkan permasalahan tersebut, membuat peneliti mengangkat masalah ini menjadi sebuah bahan kajian penelitian mengenai pengembangan media pembelajaran yang dapat digunakan untuk meningkatkan hasil belajar siswa yaitu berupa buku pop up yang disesuaikan dengan kegiatan belajar di PAUD Bougenville.

Media pembelajaran adalah segala bentuk komponen yang dapat digunakan untuk menyalurkan pesan / informasi sehingga dapat mendorong terjadinya proses belajar. (Lihat Buku Media Pendidikan, 2014, h.6-7; Belajar dan Pembelajaran Berbasis Komputer
Mengembangkan Profesionalisme Guru Abad 21, 2012, h.16o)

Media pembelajaran yang akan dikembangkan berupa buku pop up. Buku ini akan dijadikan sebagai media yang akan digunakan pada saat kegiatan bercerita. Anak dapat menggunakan buku ini dengan dampingan guru, dan anak yang bercerita di depan kelas. Buku ini berbentuk persegi panjang dengan ukuran $\mathrm{A}_{4}$, mempunyai efek pop up di dalamnya.

Buku Pop Up adalah buku yang mempunyai susunan 3 dimensi yang dapat bergerak ketika halamannya dibuka, digeser, atau ditarik. (Lihat Buku Brooklyn Pops Up! The History and Art of the Movable Book, 2004, h.12; The Pop-up Book:Step by step Instructional, 1993, h.5; Design Pop-up Child Puppet Figures Series Gatot Kaca, 2009, h.14)

Berdasarkan pertimbangan yang telah dijelaskan oleh peneliti sebelumnya, maka peneliti tertarik untuk melaukan penelitian pengembangan buku pop up tema binatang untuk kegiatan bercerita di PAUD Bougenville. Penelitian ini bertujuan untuk mengatasi permasalahan kurangnya minat dan motivasi siswa pada kegiatan bercerita.

Kegiatan Bercerita adalah suatu upaya atau perilaku yang dilakukan secara lisan yang dapat digunakan untuk melatih imajinasi serta kreatifitas anak dalam berbicara atau berbahasa. (Lihat Jurnal oleh Novfitri Kurniawati, 2018; Jurnal oleh Istirokah, 2017)

Penggunaan buku pop up dalam kegiatan bercerita mempunyai harapan dapat memberikan pengalaman baru bagi anak dan meningkatkan motivasi dalam diri anak agar tertarik pada kegiatan bercerita. Selain itu, sebelumnya buku yang sesuai dengan kegiatan bercerita di PAUD Bougenville ini belum pernah ada, peneliti sudah melakukan observasi ke beberapa toko buku di Jakarta, namun tidak ditemukan. PAUD Bougenville sendiri belum pernah menggunakan buku pop up sebelumnya dalam proses pembelajaran.

Pada umumnya, kegiatan bercerita dapat dilakukan menggunakan berbagai media pembelajaran, namun karena beberapa kendala 
yang telah peneliti jabarkan di atas maka peneliti mengembangkan buku pop up yang digunakan dalam pembelajaran di PAUD Bougenville. Dalam kegiatan menggunakan produk yang dikembangkan ini, diharapkan dapat menambah pengalaman bagi peserta didik, dapat menarik minat dan motivasi peserta didik khususnya pada kegiatan bercerita. Pengembangan ini diharapkan dapat memberikan manfaat-manfaat seperti pada penjabaran di atas.

\section{METODE}

Penelitian ini dilakukan melalui metode penelitian pengembangan yang bertujuan untuk menghasilkan sebuah produk buku pop up tema binatang yang digunakan untuk kegiatan bercerita anak di PAUD Bougenville. Dalam melakukan penelitian, peneliti menggunakan model pengembangan Baker \& Schutz.

Pengembangan produk buku pop up ini didasarkan pada tahapan yang ada dalam model Baker \& Schutz, tahapan pengembangan tersebut yaitu perumusan, spesifikasi pembelajaran, uji coba soal, pengembangan produk, uji coba produk, revisi produk, dan analisis operasi.

Penelitian ini dilakukan di PAUD Bougenville Kalimalang, Sasarannya adalah peserta didik kelompok bermain usia 3-4 tahun. Teknik evaluasi yang digunakan untuk menilai kelayakan dan kualitas produk ini adalah melalui penilaian expert review dan field test. Pada tahap expert review melibatkan satu orang ahli materi dan satu orang ahli media. Kuisioner yang digunakan pada expert review dalam penelitian ini adalah skala 4-1.

Pada penilaian field test, peneliti menggunakan lembar penilaian observasi. Pada tahap field test melibatkan 1 orang guru PAUD Bougenville untuk menilai 15 orang anak yang menggunakan produk. Kuisioner yang digunakan pada field test menggunakan skala 4-1 dilengkapi juga dengan kriteria penilaian sesuai indikator yang digunakan untuk memudahkan guru dalam menilai.

Dalam mengolah data yang telah diperoleh seluruhnya melalui kuisioner, peneliti menggunakan teknik analisis data menggunakan rumus statistik sederhana untuk mengetahui nilai rata-rata, kemudian hasil juga dianalisis dalam bentuk deskriptif sehingga dapat diambil kesimpulan.

\section{HASIL DAN PEMBAHASAN}

Pengembangan buku pop up ini dilakukan melalui tujuh tahapan sesuai dengan model pengembangan Baker \& Schutz dengan penjabaran sebagai berikut :

\section{Perumusan}

Pada tahap ini pengembang melakukan pengamatan dan wawancara tidak terstruktur dengan Kepala Sekolah di PAUD Bougenville,

a. Terdapat 3 kelas di PAUD Bougenville yaitu kelas kelompok bermain untuk usia 3-4 tahun, kelas A untuk usia 4-5 tahun, dan kelas B untuk usia 5-6 tahun.

b. Latar belakang guru di PAUD Bougenville bukan lulusan PAUD melainkan relawan dari lingkungan sekitar yang sudah mengikuti pelatihan guru PAUD.

c. Terdapat kegiatan belajar yang dianggap guru merasa sulit untuk mendapatkan minat dan motivasi dari peserta didik yaitu dari salah satu tema pembelajaran "tema binatang”, kegiatan belajar tersebut yaitu "menceritakan pengalaman / kejadian sederhana menceritakan liburan ke kebun binatang"

d. Belum adanya media pembelajaran yang dirasa tepat untuk digunakan pada kegiatan bercerita sesuai dengan tema dan kegiatan belajar.

\section{Spesifikasi Pembelajaran}

Pada tahap ini peneliti merumuskan standar kompetensi, kompetensi dasar, dan indikator yang ingin dicapai oleh peserta didik mengacu pada teori bercerita. Pada proses perumusan ini peneliti melakukan diskusi dengan guru di PAUD Bougenville serta dosen pembimbing. Berikut merupakan rumusan spesifikasi pembelajaran yang telah dirumuskan : 
Tabel 1 Rumusan Spesifikasi Pembelajaran

\begin{tabular}{|c|c|c|}
\hline $\begin{array}{l}\text { Standar } \\
\text { Kompetensi }\end{array}$ & $\begin{array}{l}\text { Kompetensi } \\
\text { Dasar }\end{array}$ & Indikator \\
\hline \multirow{4}{*}{$\begin{array}{l}\text { Anak dapat } \\
\text { mengulang } \\
\text { cerita } \\
\text { menggunakan } \\
\text { buku cerita } \\
\text { pop up sesuai } \\
\text { dengan } \\
\text { unsur-unsur } \\
\text { intrinsik } \\
\text { cerita }\end{array}$} & $\begin{array}{l}\text { Anak dapat } \\
\text { mengulang } \\
\text { cerita sesuai } \\
\text { dengan tema }\end{array}$ & $\begin{array}{l}\text { Mengulang } \\
\text { cerita sesuai } \\
\text { dengan tema } \\
\text { binatang }\end{array}$ \\
\hline & $\begin{array}{l}\text { Anak dapat } \\
\text { menyebutkan } \\
\text { tokoh yang } \\
\text { ada }\end{array}$ & $\begin{array}{l}\text { Menyebutkan } \\
\text { nama-nama } \\
\text { binatang } \\
\text { yang ada }\end{array}$ \\
\hline & $\begin{array}{l}\text { Anak dapat } \\
\text { mengulang } \\
\text { cerita } \\
\text { mengikuti } \\
\text { alur cerita }\end{array}$ & $\begin{array}{l}\text { Mengulang } \\
\text { cerita sesuai } \\
\text { dengan alur }\end{array}$ \\
\hline & $\begin{array}{l}\text { Anak dapat } \\
\text { menyebutkan } \\
\text { latar dalam } \\
\text { cerita }\end{array}$ & $\begin{array}{l}\text { Menyebutkan } \\
\text { latar dalam } \\
\text { cerita }\end{array}$ \\
\hline
\end{tabular}

\section{Uji Coba Butir Soal}

Pada tahap ini, pengembang merumuskan kisi-kisi instrumen. Kisi- kisi instrumen akan digunakan pada tahap expert review untuk menilai kualitas dari buku pop up dan field test yang akan digunakan untuk mengukur ketercapaian dari tujuan pembelajaran.

\section{Pengembangan Produk}

Pada tahap ini, peneliti membuat langkah-langkah secara sistematis yang akan dilakukan pada pengembangan produk. Berikut merupakan tahap pengembangan buku pop up tema binatang untuk Kelompok Bermain di PAUD Bougenville;

a. Menentukan Judul Buku

Peneliti menentukan judul buku menyesuaikan dengan kegiatan belajar yaitu "menceritakan pengalaman / kejadian sederhana liburan ke kebun binatang" maka judul yang ditentukan untuk buku pop up ini adalah "Liburan ke Kebun Binatang".

b. Membuat GBIM

Peneliti merumuskan GBIM (Garis Besar Isi Media) yang akan digunakan sebagai rangkuman dari pengembangan produk yang akan dikembangkan.

\section{c. Membuat Naskah Cerita}

Peneliti menulis naskah cerita yang akan menjadi acuan dalam pembuatan alur cerita dalam buku pop up.

d. Membuat Storyboard

Peneliti membuat storyboard yang akan menjadi acuan dalam pembuatan visual buku pop up. Pembuatan storyboard juga mengacu pada naskah cerita yang telah dibuat sebelumnya.

e. Membuat Desain

Peneliti mendesain visual sesuai dengan storyboard yang telah dibuat. Pada proses desain peneliti menggunakan gambar yang ada pada situs freepik dan shutterstock untuk visual yang ada di dalam buku. Untuk cover dan background di desain ulang oleh peneliti menggunakan adobe photoshop dan adobe illustrator. Berikut adalah hasil dari desain yang telah dibuat oleh peneliti;

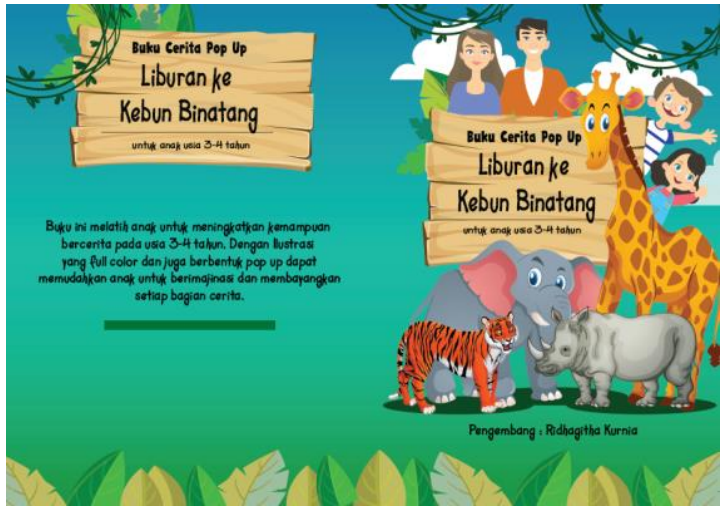

\section{Gambar 1 Hasil Desain Cover}

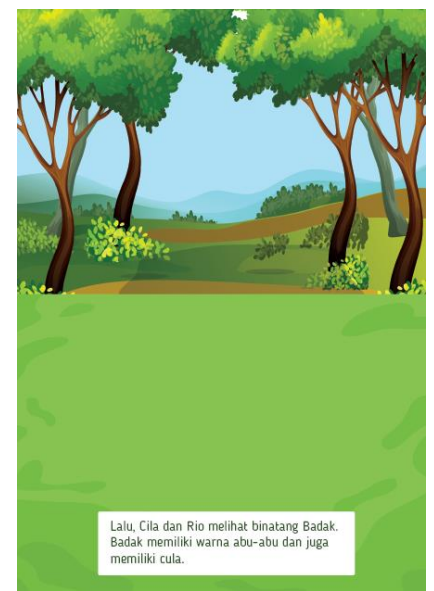

Gambar 2 Salah Satu Hasil Des ain Background 


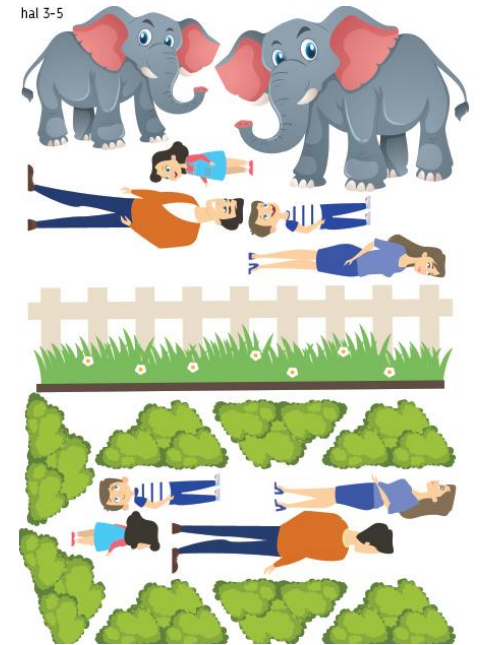

Gambar 3 Salah satu Hasil Desain Objek

f. Proses Mencetak

Peneliti melakukan pencetakan di salah satu toko percetakan di daerah rawamangun. Peneliti memilih kertas art carton 26ogsm untuk background dan objek, sedangkan untuk cover menggunakan kertas stiker vinnyl. Kertas yang sudah dicetak diberi laminasi glossy sehingga terlihat lebih menarik dan tidak mudah rusak.

g. Proses Cutting

Setelah melalui proses pencetakan, selanjutnya dilakukan proses cutting. Cutting dilakukan secara manual menggunakan gunting dan cutter. Peneliti menggunting objek satu persatu untuk menjadi isi dari buku. Kemudian, dilakukan juga cutting berbentuk persegi panjang pada art carton 26ogsm kosong untuk dijadikan sebagai penyangga efek pop up.

h. Proses penyatuan background atau latar

Peneliti melakukan tahap penyatuan background yang satu dengan yang lainnya secara manual menggunakan doubletape. Background disatukan secara berurutan menyesuaikan halaman dari buku.

i. Proses Pembuatan Efek Pop Up dan Hardcover

Pada tahap ini, peneliti menggunakan kertas art carton 26ogsm yang sudah dipotong persegi panjang untuk penyangga dibelakang objek agar dapat berdiri ketika buku dibuka. Kemudian semua objek yang sudah diberi penyangga ditempelkan ke latar sehingga menghasilkan buku pop up. Berikut adalah hasil dari salah satu halaman buku;

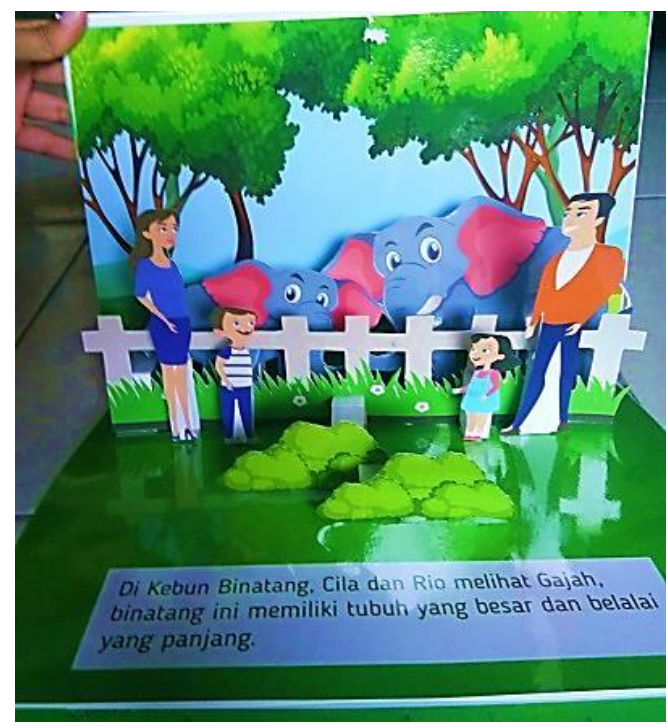

Gambar 4 Hasil dari salah satu Halaman Buku

Selanjutnya, peneliti melakukan proses hardcover buku menggunakan yellowboard ukuran $3 \mathrm{~mm}$ sebagai alas untuk menempelkan cover yang berupa stiker. Berikut adalah hasil dari hardcover buku;

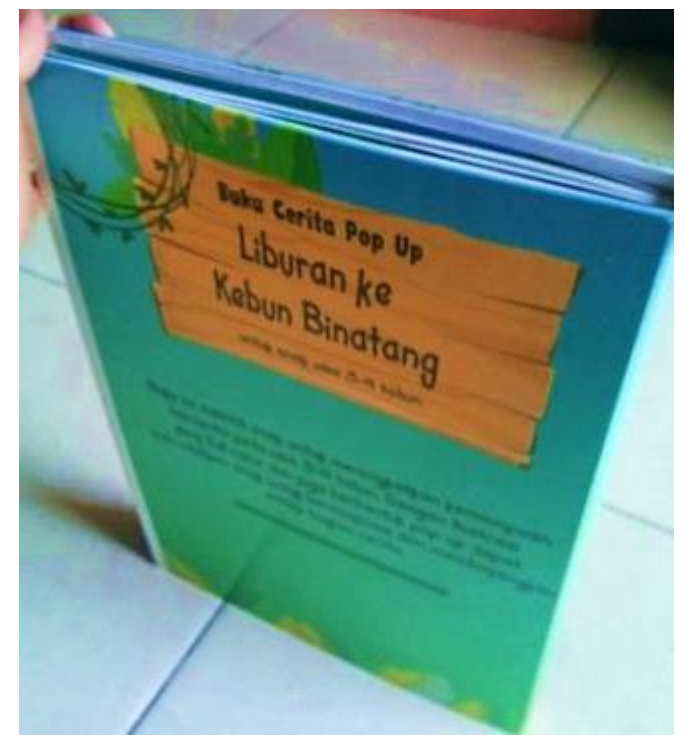

Gambar 5 Hasil Hardcover 


\section{Uji Coba Produk}

Setelah produk dikembangkan, kemudian buku pop up diuji cobakan kepada para ahli dan pengguna. Pada uji coba ahli materi, peneliti melibatkan satu orang dosen PGPAUD Universitas Negeri Jakarta yaitu Ibu Niken Pratiwi, M.Pd. Untuk Ahli Media, peneliti melibatkan satu orang dosen Teknologi Pendidikan Universitas Negeri Jakarta yaitu Bapak Kunto Imbar Nursetyo, M.Pd.

Tahap selanjutnya, peneliti melakukan uji coba lapangan dengan menggunakan penilaian observasi. Pada uji coba ini, pengembang melibatkan satu orang Kepala Sekolah PAUD Bougenville yaitu Ibu Lia Wasilah untuk melakukan penilaian observasi dan juga 15 orang siswa kelompok bermain yang akan menggunakan produk.

\section{a. Expert Review}

\section{1) Ahli Materi}

Berdasarkan hasil uji coba yang dilakukan kepada ahli materi yaitu Ibu Niken Pratiwi, M.Pd, diperoleh nilai rata-rata sebesar 3,7. Hasil uji coba tersebut menunjukan bahwa kualitas produk dari segi materi pembelajaran dapat dikategorikan sangat baik.

\section{2) Ahli Media}

Berdasarkan hasil uji coba yang dilakukan kepada ahli media yaitu Bapak Kunto Imbar Nursetyo, M.Pd, diperoleh nilai rata-rata sebesar 3,7. Hasil uji coba tersebut menunjukan bahwa kualitas produk dari segi media pembelajaran dapat dikatakan sangat baik.

Untuk itu hasil rata-rata uji coba para ahli secara keseluruhan terhadap kualitas buku pop up adalah sebagai berikut:

Tabel 2 Hasil Rata-rata Keseluruhan Expert Review

\begin{tabular}{ccc}
\hline No. & Expert Review & Rata-rata \\
\hline $\mathbf{1}$ & Ahli Materi & 3,7 \\
$\mathbf{2}$ & Ahli Media & 3,7 \\
Rata-rata Keseluruhan & $\mathbf{3 , 7}$ \\
\hline
\end{tabular}

Berdasarkan data di atas, dapat dilihat hasil yang didapatkan dari expert review diperoleh rata-rata keseluruhan sebesar 3,3. Sehingga dapat disimpulkan bahwa kualitas buku pop up tema binatang ini dikategorikan sangat baik.

b. Field Test

Pada tahap uji coba lapangan ini, peneliti menggunakan penilaian observasi yang akan digunakan guru untuk menilai ketercapaian tujuan pembelajaran kepada 15 orang siswa kelompok bermain PAUD Bougenville.

Data hasil perhitungan secara keseluruhan diperoleh presentase sebesar $88 \%$, nilai tersebut merupakan rata-rata dari beberapa aspek yang menjadi penilaian yaitu aspek tema sebesar 92\%, aspek tokoh $87 \%$, aspek alur 83\%, dan aspek latar 90\%. Maka dapat disimpulkan bahwa buku pop up yang digunakan siswa pada saat kegiatan bercerita berlangsung dapat dikatakan baik.

\section{Revisi Produk}

Pada langkah uji coba produk, peneliti mendapatkan beberapa masukan dari responden dan pengkaji. Masukan tersebut dijadikan panduan untuk menyempurnakan buku pop up. Berikut adalah saran yang telah diberikan dan telah peneliti tambahkan ke dalam produk:

a. Gambar pada cover di bagian depan semakin diperkaya dengan tokoh yang ada di dalam buku cerita

b. Gambar pada cover di bagian belakang ditambahkan, teks diganti menjadi informasi dari penggunaan buku pop up

c. Pemberian nama pada tokoh anak dalam isi cerita, yaitu "Cila dan Rio"

d. Satu halaman sebelum masuk ke dalam bagian cerita diganti menjadi kata ajakan untuk bercerita bersama, sementara alur masuk ke dalam setiap halaman cerita

e. Ilustrasi pada isi cerita semakin diperkaya 
f. Pose tokoh keluarga pada isi cerita dibuat lebih variatif mengikuti alur cerita

g. Dalam setiap halaman ditambahkan sedikit teks sebagai alur

h. Menggunakan hardcover yang lebih tebal dalam proses penjilidan

\section{Analisis Operasi}

Kelebihan dari buku pop up ini adalah buku ini dapat digunakan untuk menarik minat dan motivasi siswa karena bentuk pop up yang sebelumnya belum pernah ada di PAUD Bougenville, selain itu buku memiliki visual yang penuh dengan warna dan menggunakan kartun sebagai objeknya. Dari segi ukuran, buku ini mudah dibawa dan digunakan dalam kegiatan pembelajaran sehari-hari.

Kekurangan dari buku ini adalah proses produksi yang masih sederhana, segala proses dilakukan secara manual sehingga masih terlihat kurang rapi dan terdapat perbedaan tata letak objek ketika buku diperbanyak, selain itu dalam proses produksinya juga membutuhkan waktu jika harus diproduksi dalam jumlah yang banyak.

\section{SIMPULAN}

Penelitian pengembangan ini menghasilkan sebuah media pembelajaran berupa buku pop up tema binatang yang berjudul "Liburan ke Kebun Binatang" untuk kegiatan bercerita anak pada kelompok bermain di PAUD Bougenville. Penelitian ini menggunakan metode pengembangan dengan model Baker \& Schutz. Secara umum hasil penelitian ini ditunjukkan dengan hasil uji coba formatif produk yang dikategorikan sangat baik melalui expert review dan dikategorikan baik melalui uji coba lapangan.

\section{UCAPAN TERIMA KASIH}

Terima Kasih penulis ucapkan kepada Allah SWT, keluarga, dosen pembimbing I dan II, PAUD Bougenville, serta teman-teman yang selalu memberikan dukungan, semangat, serta do'a kepada penulis selama proses penelitian berlangsung.

\section{DAFTAR PUSTAKA}

Sadiman, Arief S dkk (2014) Media Pendidikan : Pengertian, Pengembangan, dan Pemanfaatannya. Jakarta: Rajawali Pers

Rubin, Ellen Kreinger (2004) Brooklyn Pops Up! The History and Art of the Movable Book. United State

Jackson, Paul (1993) The Pop-up Book: Step by step Instructional. London: Annes Publishing Ltd

Dzuanda, (2009) Design Pop-up Child Puppet series Gatot Kaca. Indonesia

Novfitri Kurniawati. 2018. Peningkatan Kemampuan Bercerita Menggunakan Metode Pembelajaran Talking Stick di Kelompok B TK Aisyah 66 Surabaya

Istirokah. 2018. Peningkatan Kemampuan Bercerita Melalui Media Rotasia pada Anak Didik Kelompok A1 TK Pamekar Budi Desa Candisari Kecamatan Mrangen Kabupaten Demak Semester 1 Tahun Pelajaran 2016/2017 